\title{
An unclassified Eubacterium taxon in acute dento-alveolar abscess
}

\author{
W. G. WADE*, M. A. O. LEWIS, SARAH L. CHEESEMAN†, E. G. ABSI and PATRICIA A. BISHOP \\ Departments of Oral Surgery, Medicine and Pathology and $\dagger$ Periodontology, University of Wales College of \\ Medicine, Heath Park, Cardiff CF4 4XY and * Oral Microbiology Unit, Department of Oral Medicine, Pathology and \\ Microbiology, Dental School, University of Bristol, Lower Maudlin Street, Bristol BS1 $2 L Y$
}

\begin{abstract}
Summary. The microflora of pus samples aspirated from 50 acute dento-alveolar abscesses was examined. A total of 143 bacterial strains was isolated, consisting predominantly of Prevotella spp., $\alpha$-haemolytic Streptococcus spp., Peptostreptococcus spp. and Eubacterium spp. An unclassified asaccharolytic Eubacterium taxon was encountered in $17(34 \%)$ of the abscesses. This taxon was found to have a positive association with Fusobacterium spp. and a negative association with $\alpha$-haemolytic Streptococcus spp.
\end{abstract}

\section{Introduction}

The microbial flora of acute dento-alveolar abscess was traditionally thought to consist of facultative streptococci and staphylococci, either alone or in combination. ${ }^{1,2}$ However, aspiration sampling of abscesses rather than the use of swabs revealed that the organisms previously reported were likely to represent contaminants rather than to be a true reflection of the abscess microflora. ${ }^{3}$ More recently, the use of improved methods of anaerobic incubation and identification techniques for slow growing, nonreactive strict anaerobes has revealed the frequent presence of Peptostreptococcus spp., Prevotella spp. and Fusobacterium spp. in acute dento-alveolar abscesses. ${ }^{4,5}$

Asaccharolytic Eubacterium spp. are strictly anaerobic gram-positive bacilli which, in the past, have been difficult to culture and identify. Eubacterium spp. are being implicated increasingly in chronic periodontal disease $\mathrm{e}^{6-8}$ and have been found to account for up to $50 \%$ of the anaerobic flora in subgingival plaque. ${ }^{9}$ These organisms have been isolated also from carious dentine ${ }^{10}$ and necrotic root canals ${ }^{11,12}$ but little information is available concerning their presence in suppurative periapical infection. The uncertainty of the role of these organisms in dental disease may be due in part to difficulties with the taxonomy of the group since a variety of unnamed taxa have been described. ${ }^{7,9,13,14}$

The aim of the present study was to determine the prevalence of asaccharolytic Eubacterium spp. in acute suppurative dento-alveolar infection and to detect any microbial associations between these organisms and other members of the abscess microflora.

\section{Materials and methods}

Patients with acute dento-alveolar abscess attending the Examination and Emergency Clinic of Cardiff Dental Hospital and School were included in the study. Pus specimens were obtained by needle aspiration and transferred promptly to the laboratory for processing. Pus was inoculated on to blood agar plates (Blood Agar Base No. 2, Lab M, Bury, supplemented with sheep blood, TCS Biological Ltd, Buckingham, 5\%), chocolate agar and Fastidious Anaerobe Agar (Lab M) supplemented with sheep blood $5 \%$ which were incubated in air, in air plus $\mathrm{CO}_{2}$ $5 \%$ and in an anaerobic cabinet $\left(\mathrm{N}_{2} 80 \%, \mathrm{CO}_{2} 10 \%\right.$, $\mathrm{H}_{2} 10 \%$ ), respectively. Aerobic growth was assessed after 24 and $48 \mathrm{~h}$ and plates incubated anaerobically were examined daily for 7 days in all. Representatives of morphologically different colony types were subcultured for pure growth and identified to genus level by conventional methods. ${ }^{15}$ Strains of asaccharolytic Eubacterium spp. were identified according to enzyme and protein profiles combined with analysis of metabolic end-products. ${ }^{13}$

The association between asaccharolytic Eubacterium spp. and other bacterial isolates was assessed by calculation of odds ratio as described by Socransky et al. ${ }^{16}$

\section{Results}

Pus samples were obtained from 50 patients, of whom 23 were being treated with an antibiotic at the time of sampling. A total of 142 bacterial strains was isolated with a mean of 2.9 species/abscess. The predominant isolates were Prevotella spp. (31 strains), $\alpha$-haemolytic Streptococcus spp. (30 strains), Pepto- 
Table I. Bacterial species isolated from 50 acute dento-alveolar abscesses

\begin{tabular}{|c|c|c|c|}
\hline \multirow{2}{*}{ Bacterial species } & \multirow{2}{*}{$\begin{array}{l}\text { Number of } \\
\text { isolates }\end{array}$} & \multicolumn{2}{|c|}{$\begin{array}{l}\text { Number of isolates } \\
\text { from patients on }\end{array}$} \\
\hline & & $\begin{array}{l}\text { no antibiotic } \\
\quad(\mathrm{n}=27)\end{array}$ & $\begin{array}{c}\text { antibiotic } \\
(\mathrm{n}=23)\end{array}$ \\
\hline$\alpha$-Haemolytic Streptococcus spp. & 30 & 16 & 14 \\
\hline Non-haemolytic Streptococcus spp. & 3 & 2 & 1 \\
\hline S. anginosus & 1 & 0 & 1 \\
\hline Actinomyces spp. & 4 & 0 & 4 \\
\hline Peptostreptococcus spp. & 29 & 14 & 15 \\
\hline Eubacterium $\mathrm{C}_{2}$ & 17 & 7 & 10 \\
\hline E. brachy & 1 & 1 & 0 \\
\hline E. timidum & 1 & 1 & 0 \\
\hline Saccharolytic Eubacterium spp. & 9 & 8 & 1 \\
\hline Unidentified gram-positive bacillus & 1 & 1 & 0 \\
\hline Veillonella spp. & 7 & 4 & 3 \\
\hline Prevotella spp. & 31 & 21 & 10 \\
\hline Fusobacterium spp. & 8 & 6 & 2 \\
\hline Total & 142 & 81 & 61 \\
\hline
\end{tabular}

Table II. Average odds ratios of association between Eubacterium $\mathrm{C}_{2}$ and other species isolated from dentoalveolar abscesses

\begin{tabular}{lc}
\hline Organism & Odds ratio \\
\hline$\alpha$-Haemolytic Streptococcus spp. & $0 \cdot 4^{*}$ \\
Non-haemolytic Streptococcus spp. & $0 \cdot 92$ \\
S. anginosus & 0 \\
Actinomyces spp. & 0 \\
Peptostreptococcus spp. & 0 \\
Eubacterium brachy & 0 \\
E. timidum & 0 \\
Saccharolytic Eubacterium spp. & 0 \\
Unidentified gram-positive bacillus & 0 \\
Veillonella spp. & 0 \\
Prevotella spp. & $1 \cdot 09$ \\
Fusobacterium spp. & $12 \cdot 5 \dagger$ \\
\hline
\end{tabular}

* Negative association $<0.5$.

+ Positive association $>2 \cdot 0$.

streptococcus spp. (29 strains) and Eubacterium spp. (28 strains) (table I). The spectrum of bacteria isolated from patients with no history of antibiotics in the preceding 3 months was similar to that found in patients who had received antibiotics during the preceding 3 months or were taking an antibiotic at the time of sampling.

The Eubacterium spp. isolated were slow growing, usually only appearing after incubation for 4 days but then often becoming the most numerous organism by 7 days. Of the 28 strains of Eubacterium spp., 17 belonged to the putative Eubacterium spp. Cluster 2 $\left(\mathrm{C}_{2}\right)$ described by Wade et $a l^{13}$

Analysis of odds ratios revealed that Eubacterium $\mathrm{C}_{2}$ had a positive correlation with Fusobacterium spp. and a negative correlation with $\alpha$-haemolytic Streptococcus spp. (table II).

\section{Discussion}

It is now generally accepted that the microflora of acute dento-alveolar abscesses usually contains a combination of facultative streptococci and strictly anaerobic bacteria. In recent years, improved methods of incubation and identification of strict anaerobes have revealed that Peptostreptococcus spp. and Prevotella spp. are frequently encountered in suppurative dental infections. The results of the present study suggest that the newly described taxon Eubacterium $\mathrm{C}_{2}$ is also frequently present in pus aspirated from acute dento-alveolar abscess. It is possible that previous studies of acute suppurative dental infections failed to isolate these organisms either because of short periods of incubation or problems associated with identifying non-reactive anaerobic gram-positive bacilli. Eubacterium $\mathrm{C}_{2}$ resembles $E$. lentum which is also generally non-reactive in biochemical tests. Isolates described as $E$. lentum have frequently been cultured from the root canals of teeth. ${ }^{11,12}$ The two species may be distinguished by culture on FAA, as this medium contains arginine which stimulates the growth of $E$. lentum, giving rise to relatively large colonies, whereas colonies of Eubacterium $\mathrm{C}_{2}$ remain $<1 \mathrm{~mm}$ in diameter even after prolonged incubation. ${ }^{8}$

Analysis of the microbiological findings of the present study revealed a positive association between Eubacterium $\mathrm{C}_{2}$ and Fusobacterium spp. Therefore, it is possible that these two species may interact to give enhanced pathogenic potential to the abscess flora similar to the interactions shown experimentally for other combinations of gram-positive and gram-negative strict anaerobes isolated from acute dento-alveolar abscesses. ${ }^{17}$ The negative association with $\alpha$-haemolytic streptococci is interesting and could be interpreted as supporting the proposal that the mixed flora of acute dento-alveolar abscess is initially predominantly facultative and becomes progressively strictly anaerobic with time.

In conclusion, the use of prolonged anaerobic incubation and techniques capable of identifying strictly anaerobic gram-positive bacilli have revealed 
that Eubacterium $\mathrm{C}_{2}$ taxon is frequently present in the flora of acute dento-alveolar abscesses. Further studies are required to provide information on the role of this group and other Eubacterium spp. in dental disease.

\section{References}

1. Hunt DE, Meyer RA. Continued evolution of the microbiology of oral infections. J Am Dent Assoc 1983; 107: 52-54.

2. Turner JE, Moore DW, Shaw BS. Prevalence and antibiotic susceptibility of organisms isolated from acute soft-tissue abscesses secondary to dental caries. Oral Surg Oral Med Oral Pathol 1975; 39: 848-857.

3. Lewis MAO, MacFarlane TW, McGowan DA. A microbiological and clinical review of the acute dentoalveolar abscess. Br J Oral Maxillofac Surg 1990; 28: 359-366.

4. Lewis MAO, MacFarlane TW, McGowan DA. Quantitative bacteriology of acute dento-alveolar abscesses. $\mathrm{J} \mathrm{Med}$ Microbiol 1986; 21 : 101-104.

5. Aderhold L, Knothe H, Frenkel G. The bacteriology of dentogenous pyogenic infections. Oral Surg Oral Med Oral Pathol 1981; 52: 583-587.

6. Holdeman LV, Cato EP, Burmeister JA, Moore WEC. Descriptions of Eubacterium timidum sp. nov., Eubacterium brachy sp. nov. and Eubacterium nodatum sp. nov., isolated from human periodontitis. Int J Syst Bacteriol 1980; 30: 163-169.

7. Moore WEC, Holdeman LV, Cato EP, Smibert RM, Burnmeister JA, Ranney RR. Bacteriology of moderate (chronic) periodontitis in mature adult humans. Infect Immun $1983 ;$ 42: 510-515.

8. Wade WG, Moran J, Morgan JR, Newcombe R, Addy M. The effects of antimicrobial acrylic strips on the subgingival microflora in chronic periodontitis. $J$ Clin Periodontol 1992; 19: 127-134.

9. Uematsu H, Hoshino E. Predominant obligate anaerobes in human periodontal pockets. J Periodont Res 1992; 27: $15-19$

10. Hoshino E. Predominant obligate anaerobes in human carious dentin. J Dent Res 1985; 64: 1195-1198.

11. Sundqvist G. Associations between microbial species in dental root canal infections. Oral Microbiol Immunol 1992; 7 : 257-262.

12. Wasfy MO, McMahon KT, Minah GE, Faulkner WA. Microbiological evaluation of periapical infections in Egypt. Oral Microbiol Immunol 1992; 7: 100-105.

13. Wade WG, Slayne MA, Aldred MJ. Comparison of identification methods for oral asaccharolytic Eubacterium species. J Med Microbiol 1990; 33: 239-242.

14. Hill GB, Ayers OM, Kohan AP. Characteristics and sites of infection of Eubacterium nodatum, Eubacterium timidum, Eubacterium brachy, and other asaccharolytic Eubacteria. $J$ Clin Microbiol 1987; 25 : 1540-1545.

15. Wade WG, Gray AR, Absi EG, Barker GR. Predominant cultivable flora in pericoronitis. Oral Microbiol Immunol $1991 ; 6: 310-312$.

16. Socransky SS, Haffajee AD, Dzink JL, Hillman JD. Associations between microbial species in subgingival plaque samples. Oral Microbiol Immunol 1988; 3: 1-7.

17. Lewis MAO, MacFarlane TW, McGowan DA, McDonald DG. Assessment of the pathogenicity of bacterial species isolated from acute dentoalveolar abscesses. $J \mathrm{Med}$ Microbiol 1988; 27: 109-116. 